\title{
Effect of date of transplanting on yield and yield attributing characters of aromatic fine rice in rainfed condition
}

\begin{abstract}
A field experiment was conducted at the Bangladesh Institute of Nuclear Agriculture (BINA) farm, Mymensingh, Bangladesh, during the rainfed season in June to December, 2011, with a view to study the performance of aromatic fine rice under different dates of transplanting. The experiment was carried out with four aromatic fine rice varieties (V1-BRRI dhan 34, V2-Ukunimadhu, V3-Basmati and V4-Kataribhog) and three different dates of transplanting (D1-30 July, D2-15 August and D3-30 August). The experiment was laid out in split-plot design with three replications assigning variety in the main plot and the three different dates of transplanting in the sub-plot. Experimental result showed that aromatic fine rice varieties and dates of transplanting individually had significant effect on the agronomic parameters. The combined effect differed significantly for all the agronomic characters. The highest grain yield $(3.11 \mathrm{t} / \mathrm{ha})$ was obtained in Kataribhog, which was similar to Basmati $(2.75 \mathrm{t} / \mathrm{ha})$ followed by Ukunimadhu. The highest grain yield obtained in 15 August date of transplanting $(2.93 \mathrm{t} / \mathrm{ha})$ was identical to 30 July date of transplanting $(2.88 \mathrm{t} / \mathrm{ha})$. Combined effect showed that transplanting on 30 July and 15 August produced highest grain yield by all the varieties. In later date transplanting 30 August, production of grain yield decreased. Kataribhog, Basmati and Ukunimadhu with dates of transplanting 30 July and 15 August can be suggested in rainfed condition of Bangladesh.
\end{abstract}

Keyword: Aromatic fine rice; Rain-fed condition; Transplanting date; Yield 